\title{
印尼语中汉语借词的种类研究
}

\section{Penelitian Jenis-Jenis Kata Serapan Bahasa Tionghua Dalam Bahasa Indonesia}

\author{
Herman （唐根基） \\ Program Studi Pendidikan Bahasa Mandarin Universitas Universal - Batam（世界大学） \\ Email: hermanuvers72@gmail.com
}

\begin{abstract}
摘要
印中两国之间的贸易往来、文化交流、移民杂居等各种形态的接触, 都引发了汉语 与印尼语的接触, 在接触过程中印尼语吸收了汉语词语, 成为印尼语中的借词之一。印 尼语中汉语借词的种类丰富, 为了解印尼语中汉语借词的种类, 本文从语言接触学的角 度, 以已有的资料和自建资料为基础, 采用理论研究和语料分析相结合的方法, 通过调 查分析法和对音对义法, 全面地研究印尼语中汉语借词的种类并发现：（1）按照地区语 言分类, 印尼语中汉语借词可分为汉语普通话借词、闽南方言借词、客家方言借词、粤 方言借词、从其他语言转来的汉语借词、混合语汉语借词和创新性汉语借词;（2）按照 借用的方式分类可分为形译借词、纯音译借词和音变音译借词;（3）按照同化的程度分 类可分为未完全同化的借词和印尼语化借词。
\end{abstract}

关键词：借词；印尼语；汉语；种类

\begin{abstract}
Abstrak
Hubungan perdagangan, komunikasi budaya, imigrasi dll antara Indonesia dan Tiongkok dapat menimbulkan kontak bahasa. Dalam proses kontak bahasa, bahasa Indonesia menyerap kosakata bahasa Tionghua, menjadi salah satu kata serapan dalam bahasa Indonesia. Untuk mengetahui jenis-jenis kata serapan tersebut, berlandaskan teori kontak bahasa, mengunakan metode analisa data dan perbandingan bunyi dan makna bahasa, makalah ini secara menyeluruh meneliti jenis-jenis kata serapan bahasa Tionghua dalam bahasa Indonesia. Dalam proses penelitian kami menemukan: (1) menurut klasifikasi bahasa daerah terdiri dari kata serapan Putonghua, Hokkian, Hakka, Guangdong (Yue), kata serapan bahasa Tionghua yang diserap dari bahasa asing lainnya, kata serapan bahasa Tionghua campuran dan kata serapan inofatif, (2) Menurut klasifikasi cara meminjam terdiri dari kata serapan transliterasi semua (termasuk bentuk tulisan dan bunyi), kata serapan transliterasi murni dan kata serapan transliterasi yang mengalami perubahan, (3) Menurut tingkat kedalaman asimilasi terdiri dari kata serapan yang belum secara menyeluruh terasimilasi dan kata serapan Keindonesiaan.
\end{abstract}

Kata Kunci: Kata serapan, Bahasa Indonesia, Bahasa Tionghua, Jenis-jenis 


\section{一 引言}

印尼与中国两国关系有着悠久的历史，可追溯至汉朝时期 ${ }^{1}$, 现今更为密切。印中两 国之间的贸易往来、文化交流、移民杂居等各种形态的接触，都引发了汉语与印尼语的 接触, 在接触过程中印尼语吸收了汉语词语。正如语言学家萨丕尔（Sapir, 1921:139） 所说 “语言像文化一样, 是很少能自给自足的”。说不同语言的人互相交流时, 不断互 相吸收对方有用的词来丰富自己的语言, 这种现象叫做 “借贷” , 印尼语也是如此, 与 汉语接触后，印尼语吸收了汉语词语成为印尼语中的汉语借词。

印尼语中汉语借词主要可分为两大领域, 即已入词典和未入词典的汉语借词。为了 解印尼语中汉语借词的种类, 本文尽量穷尽收集印外辞书、词典、网络文献等的汉语借 词，建成一个语料库，并梳理汉语借词的种类。

本研究的资料主要来自十本词典, 包括: R.J.Wilkinson: A Malay-English Dictionary 《马来语-英语词典》（1932）；E.St.Harahap: Kamus Indonesia《印尼词典》，(1948）; Hassan Noel Arifin:Kamus Besar Bahasa Indonesia《印尼语大词典》( 1951); Teuku Iskandar : Kamus Dewan《马来语德宛词典》(1970); Poerwadarminta: Kamus Umum Bahasa Indonesia 《印尼大众词典》（1976）; Sultan Muhammad Zainamus;Modern Bahasa Indonesia《印尼 语现代词典》；Abdul Chaer：Kamus Dialek Jakarta《雅加达方言词典》，（1976）；Yang Kui Yee: Kamus Istilah Baru Bahasa Malaysia《现代马来语（马华双解）词典》（1984）; Indrawan WS: Kamus Lengkap Bahasa Indonesia《印尼语集全词典》; 印尼教育部: Kamus Besar Bahasa Indonesia Pusat Bahasa Edisi Keempat《印尼语大词典语言中心》第四版 （2014）。此外, 也有不少来自非词典的借词, 如: 网络: www.kompas.com、www.detik.com、 Wikipedia.com、www.google.com、www.kapanlagi.com; 报纸: Kompas（指南报纸）、 Sumeks（苏南报纸）、Palembang post（巨港市报纸）；小说与杂志: See yuu（西游记）、 Wusong（武松）、Siejenkui（薛仁贵）、Sejarah kapitan Tionghoa Indonesia（印尼甲必丹 历史）、Buku sejarah Agama Tridarma Indonesia（印尼三教历史）等，共收集了 2052 个 汉语借词。

虽有学者曾研究过印尼语中汉语借词, 如: 孔远志曾在他的著作《印度尼西亚语发 展史》第六章《印尼语的借词》（1992）谈过印尼语中汉语借词等，但有几个问题还未 得到解决, 即 “种” 的问题, 印尼语中到底有多少种汉语借词, 除了闽南方言借词, 印

1 黄昆章: 《印度尼西亚华文教育发展史》, 外语教学与研究出版社, 2007.5; P.6 97 
尼语还吸收了哪种汉语借词, 可从哪个角度进行分类, 这些问题还未有研究者提起。基 于此, 本文认为, 此内容值得进行研究。

\section{二 研究方法}

本研究从接触语言学 (Contact Linguistics) 的角度, 以已有和自建语料为基础, 整 合已有的借词理论，全面、系统地对印尼语中的汉语借词的种类展开研究，以期找出其 中的一般性规律，使用文献研究法，通过借词理论，分析印尼语中汉语借词的种类。

何为语言接触? 尤里埃尔-瓦恩里希（Uriel Weinreich）（1953:1）认为, 语言接触是 同样的一群人交替使用两种或两种以上的语言; Thomason（2001：1）认为，语言接触 的最简单定义就是，同一时间、同一地点、使用不止一种语言。

为考证汉语借词的准确性，本文使用 “对音对义法和访问法”，这样可以确定借词来 源的准确性。对音对义法是指将目的词语和原词的语音和意义进行核对, 比如: 印尼语 中汉语借词 “Bakiak [bak kiak]” 其义是 “木屐”，与闽南方言词语 “木屐 [bak kiak]” 的 语音和意义核对之后发现，其音和义一模一样，这样可以肯定此借词源于闽南方言词语; 还如, “hongpau [hon bao]”, 其义是 “红包”, 此借词与汉语普通话词语 “红包 [hon bao]” 一模一样等。

除了使用对音对义法，本文也使用访问法，对于不确定的借词，本文使用访问法进 行核对，访问较了解原词语音和词义的学者或长辈，如: “encit [en tsit]（粗印花棉布）、 kapcio[kap tsio]（奢博名）、Siongka[sion ka]（钱名）”等, 虽然我们目前找不出其原词, 但在词典中说明此词是源于汉语, 访问福建华人之后, 他们认为此借词是源于闽南方言 借词。

\section{三 借词的定义}

借词有很多说法，如外来词与外来语等。在印尼语借词的说法也很多种，即 Kata Serapan（吸词）、Kata Pinjaman（借词）、Kata Pungutan（捡词）、Kata Asing（外来 词）、Bahasa Asing（外来语）等。虽然名称不同，但都指另一种语言借用另一种语言的 词语, 在印尼语, 大家常用的是 Kata Serapan（吸词）。

何为借词？ 《现代汉语词典》第六版（2012:669）：借词是从另一种语言中吸收过 来的词; 《印尼语大词典》第四版（2014）：借词亦称吸词（Kata Serapan）是从其他语 
言吸收过来的词; Harimurti Kridalaksana 的《语言学词典》（1993:159）认为, 借词是从 另外一种语言捡出来的词, 或从另外一种语言借过来的词, 之后被纳入为规范的词语。

对于 “借词” 概念的界定学术历来有两种不同的观点, 总体上分为狭义和广义两种。 狭义的定义, 如高名凯、刘正琰在《现代汉语外来词研究》（1958：8-9）中所说：把外 语中具有非本语言所有的意义的词连音带义搬到本语言里来, 这种词才是外来词。这一 观点认为音译词才是外来词, 意译词的构词材料和方法都是汉语的, 应视为汉语固有词。

广义的定义, 如周祖模、张志公、葛本仪等认为: 凡从其他语言吸收来的词都是外 来词。葛本仪在《汉语词汇研究》中指出 “所谓外来词是指源于外语影响而产生的词, 决不就是外语中原来的词。因为任何一种语言在接受外语影响时, 都要在原来外语词的 基础上再经过一番重新改造和创制的过程”, 基于这种认识, 她将意译词也视作外来词。 除此之外，罗常培（1950:18）、张世禄（1957:40-1）、赵元任（1976:184-200）、陈原 (1983:287-295) 、黄河清（1995:15-6）和邹嘉彦、游汝杰（2009:209）等认为借词不仅 包括 “音译”词，它还应该包括 “意译”词和 “形译” 词。理由是意译词虽然是用汉语 的材料构造起来的词语, 可它的词源毕竟是外来的, 词形也是在借用外来语词的过程中 产生的, 不仅表达的概念来自外语, 而且结构也不一定是汉语中原有的; 同样, “形译” 词的词源是外来的, 词义和词形也是外来的, 只要整体上意思明确, 并且通用流行, 就 应该算是 “借词” 或 “外来词”。从这里可看, 各有春秋, 各有好处。为了解印尼语中 汉语借词的种类, 本文主要从借词的音义进行分析, 只要与原来的语音和词义有关, 本 文都将它纳入为借词。

\section{四 印尼语中汉语借词的种类}

张永言的《词汇学简论》（2015: 93-98）认为, 借词可分为三种类型：（1）按照 借用的来源和时代分类; （2）按照借用的方式分类; （3）按照同化的程度分类。按照 第一种分类法, 如汉语中的借词, 先秦两汉时代时借用中亚诸语言的词语, “五四” 运 动（1919）以后较多借于英语外来词等。按照第二种分类法, 汉语里的外来词可分为借 词（音译词）、仿译词和形译词三类。按照第三种分类法, 外来词可分为完全同化的外 来和未完全同化的外来词。

基于上述理论，本文认为，印尼语中汉语借词的种类可按照借用的方式和同化的程 度分类（不谈借用的来源和时代分类）。除此之外，由于印尼华人来自中国不同地区， 
而每地区有其方言，如福建讲闽南话，广州讲粤语，梅县讲客家话等，所以本文也按照 地区语言进行分类。

\section{1 按照地区语言分类}

华人的共同语是华语（以普通话为核心），除了说华语外，来到印尼的华人也说方 言，如福建华人讲闽南话、广州华人讲广东话（粤语）、客家话人将客家话等。此种语 言和印尼语接触之后，因各种因素也被印尼语借用。印尼语到底吸收了哪种汉语方言词 语呢? 研究发现, 按照地区语言分类, 印尼语中汉语借词的种类主要可分为汉语普通话 （华语）借词、闽南方言借词、客家方言借词、粤方言借词、从其他语言转来的汉语借 词、混合语汉语借词和创新性汉语借词七种。

\section{（一）汉语普通话借词}

什么是汉语普通话？《现代汉语词典》，（第六版）: “我国国家通用语言，现代 汉民族的共同语，以北京语音为标准音，以北方话为基础方言，以典范的现代白话文著 作为语法规范 (2015:1012)。” 何为华语? 华语是以普通话为核心的华人共同语（郭熙， 2012)。基于此, 本文认为, 印尼语中汉语普通话借词除了借于现代汉语词语普通话词 语，更广的借于华语词语的借词。

从借词的拼写方法看, 由于进入印尼语的途径不同, 所以其写法也不同, 通过中国 大陆进来的，一般使用现代汉语拼音记录，如：Hongbao（红包）、Yunnan（云南）等; 通过中国台湾进来的, 一般使用台湾华语拼音记录, 如: Tzu-chi（慈济）、Yang-tse（扬 子江)、Meng-tzi (孟子); 还有, 由于借词是属于印尼语词汇之一, 为了方便发音, 适 应印尼人，所以有些借词是按照印尼语拼音写的，如： “独龙族”，汉语拼音 “dulong”, 印尼语写成 “Derung” 等。

\section{（二）闽南方言借词}

何为闽语 (闽南方言) ? 《现代汉语词典》(第六版): “汉语方言之一, 分布在福建、 台湾、海南和广东东部一带” (2015:905)。基于此，本文认为，闽南方言借词是指借于 分布在福建、台湾、海南和广东东部一带的语言或方言, 比如: “sempoa” 借于闽南方言 词语 “算盘（swipoa）”, “bakso” 借于闽南方言词语 “肉酥（baksu）”, “Becak” 借于闽 南方言词语 “马车 (bechia)”等。 
从借词的拼写方法看, 闽南方言借词的拼写方法主要有两种, 包括: 闽南方言拼音,

如: Bopeng (无平/麻脸)”、Gocap (五十)、Boen bio（文庙）和印尼语拼音，如: Tahu (豆腐)、Encik（阿姊）、Becak（马车）、Opium（鸦片）。

\section{（三）客家方言借词}

《现代汉语词典》(第六版) 认为, 客家方言（客家话）是 “汉语方言之一, 分布在 广东、福建、广西、江西、湖南、台湾等省区” (2015:737)。基于此, 本文认为, 客方 言借词是指借于汉语方言之一, 是借于客家话的借词, 比如: “Tongngin（唐人)”, “kulunyuk（咕噜肉）”, “jam mian（掩面）。

\section{（四）粤方言借词}

何为粤方言 (粤语) ? 《现代汉语词典》第六版: “汉语方言之一, 分布在广东中西 部、广西东南部和港澳地区” (2015:1610)。基于此, 本文认为, 粤方言借词是汉语方言 借词之一, 是指借于广东中西部、广西东南部和港澳地区的语言, 比如: 如: Hongkong

（香港）、Tomyam (冬炎)、Yamcha（饮茶）、Kanton (广东)、Sunyatsen (孙中山)、Songhee (双喜酒)、Sukafon（水鸡饭）等。

\section{（五）从其他语言转来的汉语借词}

印尼语是 “和谐” 语言, 吸收了相当多的外语词语, 如梵语、阿拉伯语、英语等。 由于语言是 “开放” 的, 所以上述语言与汉语接触之后也曾吸收汉语词语, 成为自己语 言的借词, 如梵语汉语借词、阿拉伯语汉语借词、日语汉语借词等。因为此种语言也与 印尼语相互接触, 所以难免也会被印尼语借用, 包括它们语言的汉语借词, 此种借词本 文命名为 “从其他语言转来的汉语借词”。此种借词的产生不是因为中国人与印尼人的 接触, 而是因为其他国家的人与中国人接触之后, 因各种因素, 借用了中国语言的词语, 变成自己语言的汉语借词, 然后, 此国的人与印尼人接触, 在接触过程中, 因各种因素, 其语言也被印尼语借用, 包括汉语借词。此外, 由于科技的发达, 现在出现很多词典或 其他著作，所以有些转来的汉语借词的产生不是因为人与人的接触，而是因为人与人写 的东西的接触。

印尼语中从其他语言转来的汉语借词丰富, 有的来自梵语汉语借词, 如: Sutra（丝 绸); 有的来自葡萄牙汉语借词, 如: Mandarin（官方语言); 有的来自阿拉伯语汉语借 
词, 如: Sino (中国); 有的来自日语汉语借词, 如: Honji (汉字)、Ramen (拉面); 有 的来自英语，如: Thypoon（台风）、Ozbek（乌孜别克族）、Konfusius（孔夫子）等。

从语音看, 从外语转过来的汉语借词都带自己语言语音的特色, 如: 日语汉语借词 带浓厚的日语语音, 如: Honji 其原音是 hanzi（汉字)、Zen 其原音是 chan（禅）、Bonsai 其原音是 penzai (盆栽); 英语带英语语音色彩, 如: Thypoon (台风)、Chiangkhaisek (蒋 介石)、Cinnamon (桂香); 梵语汉语借词带梵语色彩, 如: Sutra (丝绸), 其原音是 sutiauw 等。

除了音译借词, 转来的汉语借词也有混合语借词, 多数是有汉语词语与英语词语组 合的汉语借词, 如: Taoisme（道教主义), “Tao” 指道教的道, 来自汉语普通话词语, 而 “isme” 是指主义, 源于英语词语; Mongoloid (蒙古种), “Mong” 是指蒙古族, 而 “loid”是指 “种”，源于英语。

\section{（六）混合语汉语借词}

混合语汉语借词是指有汉语词语与其他语言词语组成的借词, 包括组成之后变成单 词和词组借词。混合语汉语借词可分为印汉语词语组成的汉语借词, 英汉语词语组成的 汉语借词，不同方言词语组成的汉语借词三种。

混合语汉语借词的产生主要有两种方法:（1）汉语普通话与方言、汉语与印尼语、 外语与汉语等相互接触, 在接触过程中, 因各种因素, 出现混合语汉语借词; (2) 印尼 人本身拥有汉语与外语背景, 或者说, 印尼人会说汉语与外语, 在这情况下, 在他的大 脑里, 此种语言相互接触, 接触过程中, 因各种因素, 出现混合语汉语借词。

从借词的结构看, 混合语汉语借词可分为混合单词借词和混合词组借词; 从借词的 语音结构看, 混合语汉语借词可分为印尼语与汉语词语组成的借词、汉语词语之间组成 的借词、汉语与其他外语词语组成的借词。

\section{（1）混合单词借词}

混合单词借词是由汉语词语与其他语言词语组成的汉语借词, 组成之后表示单词, 是独立借词、基本借词。据资料, 此种借词多数表示学术概念, 由于从英语转来的汉语 借词, 所以它的语音带英语语音色彩, 如: Konfusiusme (表示孔教主义)、Maois/Maoisme (毛泽东主义)、Taoisme (道教主义)、Mongoloid (蒙古种)、Sinofobia (中国症)、Sinologi (中国学)、Cinaisasi (中国化) 等。

\section{（2）混合词组借词}


混合词组借词是有汉语词语与其他语言词语组成的汉语借词, 包括印尼语词语与汉 语词语组成的借词、英语词语与汉语词语组成的借词、汉语普通话词语与汉语方言词语 组成的借词。

\section{1. 印尼语与汉语词语组成的借词}

印尼语与汉语词语组成的汉语借词是有印尼语词语与汉语词语结合的混合语汉语 借词，有的汉语普通话词语与印尼语词语组成的借词，如： bata Cina， bata 是指 “砖”, 而 Cina 是指 “中国”，组成之后表示 “中国砖”; 有的是汉语闽南方言词语与印尼语词语 组成的借词，如: Agama Khong $\mathrm{Hu}$, Agama 是指 “宗教”, 而 Khong $\mathrm{Hu} \mathrm{Cu}$ 是指 “孔夫 子”，组成之后表示 “孔教”。

印尼语与汉语词语组成的混合语借词, 也包括印尼语词缀与汉语词语组成的混合借 词，如：Pecinan，是由 Cina（中国）与前缀 “pe-” 与后缀 “-an” 组成的借词，组成之 后其义变为 “中华村” ; 还如, Bejibun, 是由前缀 “be - ” 与闽南方言词语 “ jibun（挤 满）”组成的借词，加词缀之后，其义从 “挤满” 变为 “更挤满” ; 另如：Secina，是 由 “Cina（中国）”和前缀 “se-”组成的借词，组成之后其义变为一种动物。

\section{2. 汉语词语之间组成的借词}

汉语词语之间组成的借词是有汉语方言或普通话词语之间组成的混合语借词，如： Sincun kionghi, 是有普通话词语 sincun（新春）与闽南方言词语 kionghi（恭喜）组成的 借词，组成之后其义表示 “新春恭喜” ; 还如, Kiunghi sinnyen，是闽南方言词语 Kiunghi (恭喜)与客家方言词语 Sinnyen(新年)组成的借词, 组成之后其义表示 “恭喜新年”。 另如: Tahu Mapo, 是由闽南方言印尼语化词语 tahu 与普通话词语 mapo 组成的借词, 组成之后表示 “麻婆豆腐”。

\section{3. 汉语与其他外语词语组成的借词}

汉语与其他外语词语组成的借词数量不少, 如: sinologi, 是由 Sino (中国) 与英语 词语 logi (学) 组成的借词, 组成之后表示 “中国学”; 还如: Hot Teh, 是由英语词语 hot (热) 与闽南方言词语 teh 组成的借词, 组成之后表示 “热茶”; 另如: Thewfu Spicy， 是由来自英语汉语借词 Thewfu（豆腐）与英语词语 Spicy（片）组成的借词，合并之后 表示 “豆腐片”。

词组汉语借词的语法有个特点, 只要是由印尼语化汉语借词与其他未印尼语化汉语 借词组成的借词，此种借词的顺序是按照印尼语语法排序的，如: Tahu Mapo，中心语 
tahu (豆腐) 在前面, 而定语 Mapo (麻婆) 在后面, 与汉语词组词语对比, 其位置相反, 中心语 “豆腐” 在后面, 定语 “麻婆” 在前面。这说明, “tahu”已完全被印尼语同化。 我们再看另外一个例子, 如: Kiunghi sinnyen (恭喜新年), 此词是按照汉语语法组成的 借词。

\section{（七）创新性汉语借词}

创新性汉语借词是指在汉语借词之基础上, 为了适应文化发展和社会生活变化的需 要而新造借词。创新性汉语借词是指在汉语借词之基础上, 为了创新, 还有, 由于在印 尼出现新事物, 而此事物与汉语借词有关, 所以被创造成一种新形式的汉语借词, 此种 借词不是源于直接模仿, 而是源于语言接触后的语言创新, 它有汉语词语与其他语言或 方言词语组成的借词, 组成之后它不是词组借词, 而是单词借词, 是独立定型的借词。 对此种借词, Haugen（1950b）认为此种借词是 “新造借词”, 他的理论说明, 借词研究 应该再走远些, 要关注创新 (creation)。他还认为, 新造借词不是源于直接模仿, 而是 源于语言接触后的语言创新。对于此种借词, Winford（2003:44）把它称为借词的有趣 副产品（interesting by-product of lexical borrowing）。

创新性汉语借词的产生, 除了因为出现新事物与创造新事物, 更为重要的是, 为了 适应文化发展和社会生活变化的需要。印尼语中很多来自不同语言的借词, 如英语借词、 梵语借词、阿拉伯语借词等, 此种借词与汉语借词相互接触之后, 有意或无意也会产生 创新性借词。一般此种借词是利用语言里已有的构词材料按照既定的构词规则产生出来 的。

印尼语中创新性汉语借词可分为印尼语与汉语词语组成的创新性借词、汉语词语间 组成的创新性借词和外语词语与汉语词语组成的创新性借词, 虽然此种类型的借词数量 不多，但富于创新。

\section{（1）印尼语与汉语词语组成的创新性借词}

印尼语与汉语词语组成的创新性借词是有印尼语词语与汉语词语组合的借词, 如: barongsai, 是由印语词语 barong（巴厘岛的一种面具舞）与闽南方言词语 sai（狮）组成 的借词, 组成之后表示 “中国舞狮” ; 还如: batagor, 是由闽南方言词语 $\mathrm{Ba}$ 和 ta 与印 尼语词语 gor 组成的借词。这里的 “ba” 是闽南方言借词 Bakso（肉酥）的简称，“ta” 是闽南方言借词 Tahu（豆腐）的简称, 而 “gor” 是印尼语词语 goreng (炒/炸) 的简称, 组成之后变成 batagor 表示炸豆腐肉丸; 另如: Cencawan, 是由印尼语词语 Cen 与汉语 
普通话借词 cawan（茶碗）组成的借词，组成之后，借用茶碗的形象命名膝盖，此词是 表示像茶碗一样的膝盖。

\section{（2）汉语词语间组成的创新性借词}

汉语词语间组成的创新性借词是指两个汉语词语组合的汉语借词, 组合成之后表示 某种事物, 是独立定型的借词, 如: Pakcik, 是由两个闽南词语组合的借词, pak 是指 “伯”，cik 是表示 “叔”，合并之后表示男长辈；还如：babanci，也是有两个闽南词 语组合的新造借词, baban 是指 “baba 爸爸” , ci 是指 “婶” , 合并之后表示一种食物; 另如: sambuk，是由闽南方言词语间组成的借词， sam 是指 sampan（舢板）中的 sam, 而 buk 是闽词语“木”，合并之后表示木船只。

\section{（3） 外语与汉语词语组成的创新性借词}

外语与汉语词语组成的创新性借词包括英语与汉语词语组成的创新性借词等。英语 词语与汉语词语组成的创新性借词是指印尼语中英语借词与印尼语中汉语借词组成的 词, 组合之后表示另一个事物，如： bemo，是由闽南方言借词 becak（马车）的 “be” 与英语借词 mobil (汽车) 的 “mo” 组合的借词, 合并之后表示三轮汽车; 还如: helicak, 是由英语借词 helikopter（小飞机）中的 “heli” 与闽南方言借词 becak (马车) 中的 “cak” 组成的借词, 组成之后表示像三轮车一样的小飞机。

\section{2 按照借用的方式分类}

张永言《词汇学简论》（2015: 93-98）认为, 按照借用的方式分类, 汉语里的借词 可分为音译词、仿译词和形译词三类。基于此, 本文认为印尼语中汉语借词可分为纯粹 的形译借词、音译借词和音变音译借词三类。

\section{（一）形译借词}

印尼语的文字是拉丁字母文字, 而汉语文字是意音文字, 是用表意体系的符号表示 汉语的词或语素, 即汉字。为方便大众了解汉语, 除了汉字外, 也有汉语拼音, 汉语拼 音是用拉丁字母拼写的。

汉语词语被印尼语借用之后, 除了使用印尼语拼音字母写, 也有些使用汉语拼音字 母记录, 是连音带义带形 (汉语拼音) 的借词, 此种借词本文命名为形译词, 它的文字 完全使用汉语拼音记录，比如： beijing [bei tcin]（北京）; cawan [tsha wan]（茶碗）; hongbao[xon pao] (红包); shaolin [saolin]（少林）。

\section{（二）纯音译借词}


纯音译借词是指读音相似或相近的借词, 是不用本国语素进行任何替换的借词, 是 指词音和词义, 完全借用于原词, 没有产生任何演变, 比如: 普通话借词 hongbao [xon pao]（红包）、lihai[li hai]（厉害）、long[lon]（龙）等; 闽南方言借词 samkao [sam kao] （三教 ‘儒释道”）、bocengli [bo tsey li]（无情理）、anglong [ang long]（走廊）等; 客家 方言借词 chang [tsang]（郑）、chew [tseu]（周）、fanngin [fan ngin]（番人）、chunyen [tsun yen] (春联) 等; 粤方言借词 wong [won]（王）、ceongsam [tsheon sam]（长衫）、kungfu [kuy fu] (功夫) 等。

\section{（三）音变音译借词}

音变音译借词是指在纯音译借词之基础上, 借词的语音产生一点演变, 有的某中语 音被替换, 也有的被省略或添加, 演变之后还带汉语语音色彩, 此种借词很多, 能产生 演变的主要原因是因为语音系统的差异、语音方案得到改进、说话习惯、无意而变、词 缀借词、借词的语音缺乏印尼语色彩。

\section{(1) 语音系统的差异}

印尼语语音系统与汉语语音系统各有春秋、各有特色, 有些汉语语音印尼语中没有, 如: 声调、尧舌音、送气音、鼻化韵、带鼻化韵的入声韵等。此种语音进入印尼语之后, 一般都被替换，下面其例:

\section{1. 越舌音}

普通话里的翘舌音 “ $\mathrm{zh}[\widehat{\mathrm{tS}}] 、 \mathrm{ch}\left[\widehat{\mathrm{tS}}^{\mathrm{h}}\right] 、 \mathrm{sh}[\mathrm{s}] 、 \mathrm{r}[\mathrm{t}]$ ”, 入印尼语之后都被读成平舌音 “ $z[\mathrm{ts}] 、 \mathrm{c}\left[\mathrm{ts}_{\mathrm{h}}^{\mathrm{h}}\right] 、 \mathrm{~s}[\mathrm{~s}] 、 \mathrm{r}[\mathrm{r}]$ ”，如：上海（Shanghai [say xai]）中的 “shang”，尧舌音 “sh [s]” 被读成 “s[s] ”, 变成 “[say hai]”, 虽然其写法是汉语拼音, 但其读音是印尼语读音。

\section{2. 送气音}

汉语里的送气音（包括方言） “ $\mathrm{p}\left[\mathrm{p}^{\mathrm{h}}\right] 、 \mathrm{t}\left[\mathrm{t}^{\mathrm{h}}\right] 、 \mathrm{k}\left[\mathrm{k}^{\mathrm{h}}\right] 、 \mathrm{q}\left[\mathrm{t}^{\mathrm{h}}\right] 、 \mathrm{ch}\left[\mathrm{ts}^{\mathrm{h}}\right]$ ” 等，入印尼语之 后，一般被读成不送气音 “ $\mathrm{p}[\mathrm{p}] 、 \mathrm{t}[\mathrm{t}] 、 \mathrm{k}[\mathrm{k}] 、 \mathrm{q}[\mathrm{t} \mathrm{t}]$ 、 $\mathrm{ch}[\mathrm{ts}] ” ，$ 如：汉语普通话借词 “ $\mathrm{t}\left[\mathrm{t}^{\mathrm{h}}\right]$ 变为 $\mathrm{t}[\mathrm{t}]$ ”, 比如: Taiwan [thai wan] (台湾) 被读成[tai wan]; 闽南方言借词 “ $\mathrm{k}\left[\mathrm{k}^{\mathrm{h}}\right]$ 变为 $\mathrm{k}[\mathrm{k}]$ ”, 比如: 骂气 ([ma khi]) 被读成 maki[ma ki]; 客家方言借词 “ $\mathrm{ch}\left[\mathrm{ts}^{\mathrm{h}}\right]$ 变为 $\mathrm{ch}[\mathrm{ts}]$ ”, 如: 谢 ([tshia]) 被读成 chia[tsia]; 粤方言借词 “[ $\left[\mathrm{ts}^{\mathrm{h}}\right]$ 变为 [ts]”, 如: 永春 ([win tsheon]) 变为 wingchun [win tsun]等。

\section{3. 鼻化韵}

带鼻音的韵母被称为鼻化韵, 比如闽南方言里的鼻化韵 “[ã]、[ī]、[õ]、[ē]”, 入印 
尼语之后变为普通元音 “ $[\mathrm{a}] 、[i] 、[0] 、[e]$ ”, 如: “算盘 ( $\left[\operatorname{su}^{5}{ }^{5}\right.$ pua $\left.\left.\tilde{a}^{2}\right]\right)$ 变成 soepoa[soe poa], 后来变为 sempoa”，还有，闽南方言 “[ã ] 变为 [a]”，如：香散（[hiõ suã]）变为 hiosoa [hio soa]; “[吕] 变为 $[\mathrm{o}]$ ”, 如: 豆浆 ([tau tsiõ $]$ ) 变为 tauco [tau tso]; “[ī] 变为 [i] ”, 如: 铁鞭 ([thih pī] ) 变为 tikpi[tik pi]等。

\section{4. 浊音}

印尼语语音系统里有较丰富的浊音, 如: [b]、[d]、[g]等, 这些音, 汉语普通话语音 系统里没有，但汉语方言里有，如闽南方言。

由于汉语普通话里没有浊音, 有些借词的写法是按照现代汉语拼音字母写, 此种字 母在印尼语被读成浊音, 所以此种音入印尼语之后产生演变, 比如: 现代汉语拼音中的

“b、 $d 、 g ” ，$ 虽然在汉语拼音中，此字被读成清音 $[\mathrm{p}] 、[\mathrm{t}] 、[\mathrm{k}]$ ，由于其字母是 “ $b 、 d 、$ $\mathrm{g}$ ”, 所以印尼人将此种字读成浊音[b]、[d]、[g], 譬如: Beijing [peitcin]（北京）被读成 “[bei tcin]”; daoshu [tao su]（刀术）被读成 “[dao su]”。

\section{5. 押韵}

印尼语与闽南方言的语音系统中都有押韵, 如: “[-p]、[-t]、[-k]”, 虽然此两种语言 都有押韵，但有些不带押韵的闽南方言词语，入印尼语之后被读成押韵词，如：“衰 ([sue])”，入印尼语后变成 “ soak [soak]”，后面加押韵 “[-k]”; “青盲（[tshe me]）”，入 印尼语后变成 “cemeh [tse meh]”，后面加押韵 “[-h]”。

除此之外，也有些其押韵相互替换，如：粤方言借词 “扁食（[pin sik]），入印尼语 之后变为 “pangsit [pan sit]”，后音节尾音 “ $[-\mathrm{k}]$ ” 被 “[-t $]$ ”代替等。

\section{(2) 语音方案得到改进}

印尼语语音方案曾经过多次改进, 1973 年改为《被完善的印尼语语音方案》（Ejaan Bahasa Indonesia yang disempurnakan “EYD”），其中旧音 “oe”被改为 “u”，旧音 “au” 被改为 “o”, 旧音 “ia” 被改为两个音节 “i-a” 等, 如: “算盘[ $\operatorname{su}^{-5}$ puã $\left.\tilde{a}^{2}\right]$ ”, 期初其词音 是 “Soepoa[soe poa]”, 后来变为 “Sempoa[sem poa]”, 前音节元音 “[oe]” 变为 “[em]”。

\section{（3）印尼人说话的习惯}

习惯语是个别的社会集团为了自己的利益或偏好企图在语言方面特殊化而创造出 来的词语（张永言, 2015:84)。从这段话看, 习惯语也会使语言产生演变。在印尼语, 这种现象也有, 比如: 印尼人常常将尾音读成粗一点、轻一点、往喉咙靠, 或者说, 常 常将尾音读成押韵，如将尾音加 “[-k]、[-t]、[-p]、[-I]”，比如：“笔画”，入印尼语之后 
被读成 “bihuak [pi huak]”，还有，由于印尼人常常将尾音加押韵音，所以不加押韵的汉 语词语变为押韵借词, 比如: “妈 ( $\mathrm{ma}[\mathrm{ma}])$ ” 变为 “[mak]”, 后音节尾音加押韵 “[-k]” 等。

此外, 由于印尼语有颤音 “[r]”, 所以汉语与印尼语接触后后, 有些词语被借之后 其尾音加颤音 “[r]” , 如: “橄榄 ( [Kã na] )” 变为 “Kanar [ka nar]”。还有, 有些语音 产生演变, 如: “讲古”, 其原音是 “[koy ko]”, 入印尼语之后, 有两种读音, 即语音不 变的借词, 即 “kongko[kon ko]”, 语音演变的借词, 即 “kongkow[kon kow]”, 尾音加了 “[w]”。

\section{（4）无意而变}

有些借词, 因词典记录问题, 其音产生演变, 如: 《印尼语汉语词典》(2014) 中的 “新年快乐” 被写成 “In nian kuai le”，这里的 “In” 是指 “xin”，可能因为编词典者分 不清此词的准确性，可能因为写错字，或者故意这样写，所以“x”被省略。

由于每个人对语音的感觉不同，所以当印尼人听闽南音时，因各种因素，其音产生 演变, 此种演变是无规律的演变, 是凭感觉而变, 有的被省略, 有的被替换或添加, 如: “灯膏”，其原音是 “tengko [ten ko]”，后来变为 “tebko[teb ko]” 等。

\section{（5）词缀借词}

词缀借词是指在词根之基础上, 借词的语音被加前缀、后缀或前后缀, 此种借词主 要可分为词义不变与词义演变的词缀借词。

\section{1. 词义不变的词缀借词}

词义不变的词缀借词是指加了词缀之后借词的含义没有产生演变, 此种借词最多出 现在亲属称谓借词。由于印尼人说话时常常加前缀 “ [em-]、[en]、[en], 所以在这情况下, 有些借词入印尼语之后，被加此前缀，被加之后，其义不变，比如：“伯”，其原音是 “[peh]”，入印尼语之后变成 “Pek[pek]”，由于印尼人说话时常加前缀 “[em- $]$ ，所 以它变成 “Empek[em pek]” ; “公” ，其原音是 “[kon]”，入印尼语之后语音不变，即 “Kong[kon]” , 由于印尼人说话时常加前缀 “[en-]” , 所以它变为 “Engkong[en kon]” ; “姊”，其原音是 “[tsi]”，入印尼语之后变成 “Cik[tsik]”，由于印尼人说话时常加前 缀 “[en-]” ，所以它变为 “Encik[en tsik]” 等。除了亲属称谓借词外，也有其他借词也被 加词缀，如：“龙眼（果）”，其原音是 “[lin gin]”，入印尼语之后变成 “Lengkeng[len ken]” , 由于印尼人说话时常加前缀 “[ke-]” ，所以它变为 “kelengkeng[ke len ken]”。 


\section{2. 词义演变的词缀借词}

词义演变的词缀借词是指加了词缀之后借词的含义产生演变的借词, 在印尼语此种 词缀是已成系统, 如: 前缀 “be-”, 它可以表示正在, 前缀 “se-” 可以表示相互等。在 闽南方言借词中此种借词不多，比如：“讲古”，其原音是 “[kog ko]”，入印尼语之后有 的词音不变, 即 “kongko[koy ko] (勾搭)”, 也有的被加前缀 “ [se-]” 变成 “ sekongkol[se koy kol]” , 其义变为相互勾搭; “挤满”, 其原音是 “[tse buan]”，入印尼语之后变成 “jibun[dzi bun]”，其义是挤满，加前缀 “[be-]” 之后变成 “bejibun[be dzi bun]”，其义变 成表示更多、更挤满; “荆”，其原音是 “[tsin]，入印尼语之后变成 “cina[tsina]”，其义 是中国，被加前缀 “[pe-]” 与后缀 “[-an]”之后变成 “pecinan[pe tsi nan]”，其词义变为 “华人村”。

\section{（6）借词的语音缺乏印尼语色彩}

印尼语闽南方言借词中, 有不少借词的语音带浓厚的闽音色彩, 如: “不使（不可 以）被称为 “besai[be sai]”，很明显的，它带浓厚的闽音色彩。此种类型的借词，入印 尼语之后, 因印尼语色彩不够, 所以产生演变, 如 “烧肚”, 闽南方言叫 “ [ siau to ]”, 据 1948 年的词典《印尼词典》, 它变为 “saoto[sao to]” , 后来, 据 1951 年编的词典《印 尼语大词典》，它变为 “soto[so to ]”, 中间的 “[a]” 音被省略, 省略后已不像闽南方言 词语。

\section{3 按照同化程度分类}

从同化程度看, 汉语借词可分为未同化程度借词和印尼语化借词。

\section{（一）未完全同化借词}

未完全同化借词是指语音和词义未融入至印尼语的借词, 从语音看, 其语音还带浓 厚的汉语语音, 语音没有产生演变; 从词义看, 借词背后的东西还未融入至印尼文化, 一般不属于生活中常用的借词, 其使用范围不广, 属于地区性借词, 有些借词印尼语中 也有其同义词，它相当于纯音译借词或产生一些语音演变的音译借词，下面其例:

汉语普通话借词: pakua[pa kua]（八卦), bianlian[pian lian] (变脸), hangzhou[xay

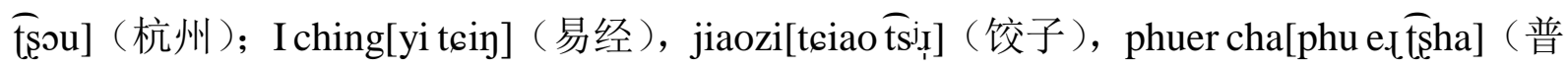
洱茶), Zhongguo[ţ̦o kuo]（中国）等。

闽南方言借词: amho[am ho] (暗号), ampai[am pai]（安排), bongsua[boy sua] (墓 山 )”, ciahun[tsia hun]（食熏), coki[tso ki]（做祭), kapcio[kap tsio]（盖笑), laukeh[lau 
keh] (老客), yanswat[yan swat] (演说) 等。

客家方言借词: chunyen[tsun yen] (春联), konyan[ko nyan] (过年), pakmeh[pak meh] (伯母), hakka[hak ka] (客家) 等。

粤方言借词：wong[woy]（黄), kwok[kwok]（郭), tongyan[ton yan]（唐人）等。

上述的借词都属于未完全同化的借词, 虽然带着浓厚的原音, 但在交流过程中也有 不少印尼人在用它, 此种借词有可能渐渐走向印尼语化借词。

\section{（二）印尼语化借词}

印尼语化借词是指同化程度深的汉语借词, 或者说, 此种借词已完全被同化。印尼 语化借词可从两种角度断定，即语音完全被同化和词义完全被同化。

\section{（1）语音印尼语化}

语音印尼语化借词是指借词的语音已完全被同化成印尼语式的借词, 使借词的语音 带印尼语的色彩, 此种借词的语音完全适应印尼语。汉语普通话词语被借后, 其语音是 被最大限度地纳入到印尼语的语音系统里加以改造。被同化的主要原因有三, 即语音系 统的差异、印尼人说话的习惯和被印尼语方言的影响, 如普通话借词 “布朗族”, 原来的 语音是 “bulang[pu lay]”, 后来变为 “blang[blay]”, 中间的 “ $u$ ” 音被省略, 清音 “b[p]” 被读成浊音 “ $[\mathrm{b}]$ ”, 两个音节变成一个音节 “Blang”; “独龙族”, 原来的语音是 “dulong[tu lon] )”, 后来变为 “derung[de rup]”, 中间的 “1[1]” 被被颤音 “ $\mathrm{r}[\mathrm{r}]$ ” 代替; “门巴族”, 原 来的语音是 “menba[men pa]”, 后来变为 “monba[min ba]”, 中间的 “[e]” 被 “[o]” 代 替, 清音 “[p]” 被读成浊音 “[b]”。

除此之外, 在研究过程中本文发现, 闽南方言词语被印尼语借用之后, 因各种因素 产生以下几个规律:

一是, 只要是 “be” 开头, 或 “cak” 结尾的交通工具借词, 它定是有闽南方言词语 “马车” 组成的词语, 组成之后表示另一种交通工具, 如: “bemo” 表示三轮汽车, “be” 是 “马 (车)”, “mo” 是指印尼语 “mobi1 (汽车)”;

二是, 只要带 “bak” 音节的食物借词, 它定是有闽南方言词语 “肉” 组成的借词, 是表示肉食, 或在 “肉” 之基础上而发展出来的一种食物, 如 “batagor” 表示炸肉丸豆 腐, “ba”是肉, “ta” 是豆（腐），“gor”是印尼语 “goreng (炒)”;

三是, 只要带 “ $k \mathrm{ki}$ 音节, 是表示心情的借词, 它定是有闽南方言词语 “气” 组成 的借词, 其义是在人 “气”之基础上而变的词语, 如: “maki (咒骂)、keki (激气)、 
dengki (恨气)”等, 后音节 “ki” 都表示 “气”;

四是, 只要带 “bo” 音节的 “无或没有” 借词, 它定是有闽南方言词语 “无” 组成 的借词, 组成之后是表示没有或无, 或者在 “无” 之基础上而发展出来的一种词语, 如 “botak (无发)、bopeng (不平)、bolos (不来)、bolui (没钱)”等，前音节 “bo” 都 表示 “无或不”;

五是, 只要带 “tok” 音节的 “啄 (敲)” 词语, 它定是有闽南方言 “啄” 组成的借 词, 是表示敲或啄的词语, 或者在 “啄” 之基础上而发展出来的一种词语, 如 “ketok(敲)、 totok（点穴）、Catuk（直啄）”等，后音节 “tok” 都表示 “啄（敲）”。

\section{（2）词义印尼语化借词}

除了语音印尼语化, 也有不少词义印尼语化。词义印尼语化借词是从借词的意义来 断定其同化程度, 有的语音产生演变, 也有些语音不变。被称为词义印尼语化的主要原 因是，借词背后的事物已融入至当地文化、借词的使用范围广、使用时间比较长等，同 化程度深, 使感觉不到其原词的色彩。

\section{1. 融入当地文化的借词}

语言是活的, 除了交际工具, 它背后也藏着一种文化。汉语也是如此, 融入印尼语 的时间久了, 其背后的事物逐渐也会融入印尼当地文化, 融入之后, 它已完全属于印尼 文化之一, 如: “肉酥 (肉丸)”, 印尼语叫” bakso[bak so]”, 闽南方言叫 “[bak su]”, 虽然其音没有产生演变, 属于纯音译借词, 但其义已融入至当地文化, 属于印尼饮食文 化借词之一, 此物, 在马浪市, 被称为 “bakso Malang (马浪市肉酥) ” 等。还如: “伯 伯（借 “伯伯”此名命名巨港食物）”，印尼语被叫 “pempek [pem pek]”, 其原音是 “[peh peh]”，是巨港市的美食之一，是巨港人借用 “伯伯” 来命名此物，被称为 “pempek Palembang”，有些人翻译成 “鱼饼”，也有些人翻译成 “大饺子”。为什么被称为 “伯 伯?”这因为此食物是由一位 “伯父” 创造出来的, 他以它为生, 由于卖主是位伯父 （pek），所以买人将此食物称为 “伯伯”，印尼语叫做 “pempek”，此食物已完全融 入当地文化。

\section{2. 生活中常用的事物}

除了上述原因, 也有些借词背后的事物日常生活中常见, 离百姓很近, 如: “茶钴” 印尼语叫 “teko[te ko]”, 闽南方言称 “[te ko]”、“锅铝” 印尼语叫 “kuali[ku a li]”, 闽南方言称 “[koli]” 等, 这些都属于厨房用品, 每天大家都会用, 虽然其音与其原音相 
近，但印尼中没有其同义词，此种词已完全被同化。还有，卫生用品 “鸡毛筅 (kemoceng[ke mao tsen] $)$ ， “粪斗（puntau[pun tau]）”、“粪箕 (pungki[pun ki] ) ” 等; 服饰用品 “玉（giok[gi ok]）”、“耳环（giwang[gi way]）”等，这些都是日常生 活中常用的东西, 并已融入至印尼文化。

民以食为天, 对百姓来说, 填饱肚子是非常重要的事情, 不管是来自哪个国家的食 物, 只要它是生活中重要食物之一, 或者它是百姓的主食, 定会被接受, 华人做的食物 也是如此, 如: “面”, 印尼语叫 “mi[mi]”, 闽南方言是 “[mi]”, 虽然是有华人发现 的, 但它属于印尼主食之一, 已完全融入印尼文化; 还如, “茶”, 印尼语叫 “teh[teh]”, 闽南方言称 “[te]”, 此饮料每天印尼人都会接触, 是印尼人的重要饮品之一。印尼有一 句老话: “早上吃点心要陪热甜茶 (teh manis)、中午吃午餐要喝乌冰茶（teh obeng）、 晚上睡觉之前喝点热苦茶（teh panas）”，这说明 “茶”已完全融入印尼文化。

\section{3. 重要称谓}

有些称谓借词, 在印尼语中没有其同义词, 如: “媒人婆（macomblang[mak tsom lan]）”, 这是中国人娶亲时常请来的媒人婆, 随着华人的到来, 印尼人也接受此文化, 现在娶亲时, 印尼人也会请媒人婆做媒人, 就用此词来称呼她。

此外, 在工作中, 我们怎么叫老板、怎么叫工人, 这些称谓都很重要, 有些印尼语 没有其同义词，属于印尼语中的基本词语之一，如：“头家”, 印尼语叫 “toke[toke]”, 以前表示头家，现在表示老板；“苦力”，印尼语叫 “kuli[ku li]”，是粗工人员的意思; “土工”，印尼语叫 “tukang [tu kay]”, 是员工的意思等, 这些借词都已完全被同化成 印尼语化借词。

\section{4. 医学借词}

有不少中国医学的词语已进入印尼语, 甚至已被纳入为印尼语中的借词之一, 但因 为其使用范围不广、使用时间不久、使用人不多等, 所以很难变为印尼语化借词, 如: “片仔癀（binahong[bi na hoy]）” 等。虽然如此, 有些中国医学借词的使用率高、使用 范围广、使用人多、使用时间较久, 生活中百姓常用, 甚至有些已被纳入为印尼医学之 一，如：“膏药（koyok[ko yok]）”、“先生（大夫）（sinse[sin se]）”、“无平（麻 脸）（bopeng[bo pey]）” 等, 此种医学借词, 生活中重要借词之一, 已完全融入印尼文 化, 成为印尼语中的基本词语之一。

\section{五 结语}


印尼语汉语借词是通过比较复杂的过程而产生的，有的因为贸易交往、文化交流、 复杂杂居、网络交流等, 也有的因为印尼人与华人相互交流, 也有的因为华人与华人相 互交流, 印尼人与印尼人交流, 还有, 通过阅读或翻译而产生的。这说明, 只要有接触, 汉语借词有可能会产生。

汉语借词主要有两宗七类, 两宗是指印尼语中汉语借词来自汉语普通话或华语的词 语和汉语方言词语, 而七类是指汉语普通话借词、闽南方言借词、客家方言借词、粤方 言借词、从其他语言转来的汉语借词、混合语汉语借词和创新性汉语借词。按照借用的 方式分类, 印尼语中汉语借词可分为形译借词、纯音译借词和音变音译借词; 按照同化 的程度分类，印尼语中汉语借词可分为未完全同化的汉语借词和印尼语化汉语借词。

\section{参考文献}

[1] 北京语言文化大学文华学院： 《语言与文化论从》，华语教学出版社，2000 年。

[2] 蔡力哲: 《晋江地区华侨史料拾捜》，华侨史，1983，第 108 页.原著: G.W.史金纳 《爪哇的中国人》（G.Willam Skinner:The Chinese of Java）。

[3] 常笑: 《英语中汉语借词的词汇化研究》, 山东师范大学硕士学位论文, 2013 年。

[4] 陈胜利: 《英语中的汉语借词研究一一接触语言学视角》, 苏州大学, 2014 年。

[5] 陈晓锦、张双庆: 《首借海外汉语方言国际研讨会论文集》, 暨南大学出版社, 2009 年 11 月。

[6] 德-弗玲斯: 《荷印的科学和科学家》 (Science and Scientist in the NederlandsIndies,1945）。

[7] 杜尔: 《印度尼西亚的华侨》。

[8] 方欣欣: 《语言接触三段两合论》, 武汉: 华中师范大学出版社, 2008 年。

[9] 郭古兮: 《语言学教程》, 西安: 陕西人民出版社, 1987 年。

[10］郭熙： 《华语研究录》，商务印书馆，2012 年。

[11] 郭熙: 《语言与语言应用论稿》, 浙江大学出版社, 2004 年。

[12] 郭熙: 《中国社会语言学》，北京：商务印书馆，2013 年。

[13］洪丽芬，罗荣强：《闽南语与马来语的词汇互借现象》，文化迁徒与交流，2012 年。

[14］黄琛芳：《印尼语语音》，智力出版社，1991 年。

[15］黄昆章: 《印度尼西亚华文教育发展史》，外语教学与研究出版社，2007 年。

[16] 孔远志: 《印度尼西亚语发展史》, 北京大学出版社, 1991 年。

[17］孔远志： 《中国印度尼西亚文化交流》，北京大学出版社，1999 年。

[18］林宝卿： 《闽南方言与古汉语同源词典》，厦门大学出版社，2002 年。

[19］刘扳盛：《广州话普通话词典》，商务印书馆，2013 年。

[20] 帕西, P.著, 刘复译: 《比较语音学概论》, 人民东方出版传媒, 东方出版社, 2012 年。

[21］萨繆-比尔在译：《法显传》。

[22] 沙加尔, 徐世璇: 《哈尼语中汉语借词的历史层次》, 中国语文, 2002 年。

[23] 托马斯·斯坦福·莱佛士：《爪哇史》。 
[24] 唐根基（Herman）： 《印尼语中汉语借词研究》，暨南大学，2016 年。

[25］袁炎：《语言接触与语言演变》，民族出版社，2000 年。

[26] 张嘉星: 《印华大词典补借词》, 未刊稿, 2011 年。

[27］邹嘉彦、游汝杰: 《语言接触论集》，上海教育出版社，2003 年。

[28］访问金洪跃，巨港市，2016 年 1 月 30 日。

[29] Abdul Chaer: Kamus Dialek Jakarta 《雅加达方言词典》, 1976.

[30] Andri Wang: Dao De Jing, Penerbit Kompas Gramedia, 2002.

[31] Assa Rahmawati: Kata Serapan Bahasa Hokkian Subdialek Xiamen Dalam Bahasa Indonesia, Universitas Indonesia. 2005.

[32] Coedes, George, (1930), Les inscriptions malaises de Çrivijaya, BEFEO

[33] Creutzberg dan van laanen. 1987. Sejarah Statistik Ekonomi Indonesia. Jakarta: Yayasan Obor.

[34] Departemen Pendidikan dan Kebudayaan Indonesia: Kamus Besar Bahasa Indonesia Pusat Bahasa Edisi Keempat, Penerbit Gramedia, 2014.

[35] E.B.Tylor, On a Method of investigating the Development of Institution, J.A.I.XVIII, 1889.

[36] E.Foechrie：Soerat Chabar Bahasa Melajoe（《马来文报》），泗水，1856.

[37] E.St.Harahap: Kamus Indonesia《印尼词典》，（1948）.

[38] Edward Sapir, Language.

[39] Ely Triasih Rahayu: Pembentukan dan Penulisan Kata serapan Dari Bahasa Inggris ke Dalam Bahasa Jepang, Universitas Diponegoro Semarang, 2005.

[40] Harimurti Kridalaksana, Kamus Linguistik, Jakarta: PT.Gramedia. 2002:122.

[41] Hassan Noel Arifin：Kamus Besar Bahasa Indonesia 《印尼语大词典》，1951.

[42] Herman Jacobi, "Kultur-, Sprach- und Literarhistorisches aus dem Kautilīya", Sitzungsberichte der Königlich- Preussischen Akademie, XLIV (1911).

[43] Histori.id/kuliner/sejara-tahu-tahu-sejarah

[44] http://hurahura.wordpress.com/2011/03/21/kuburan-tionghoa-di-batavia/

[45] http://id.wikipedia.org/wiki/Daftar_kata_serapan_Bahasa_Melayu

[46] Indiyah Imran: Kata Serapan Dalam Bahasa Indonesia, Depok: Universitas Gunadarma, 2005.

[47] Indrawan WS: Kamus lengkap Bahasa Indonesia, penerbit lintas Media Jombang.

[48] Jumariam: Senarai kata serapan dalam bahasa Indonesia, Jakarta: Depdikbud.1996:8.

[49] Keputusan presiden nomor 19 tahun 2002.

[50] Keputusan Presiden: Pasal 2 Undang-undang nomor 2006.

[51] Koran Kompas.

[52] Koran Palembang Post.

[53] Koran Sumeks.

[54] Poerwadarminta: Kamus Umum Bahasa Indonesia 《印尼大众词典》, 1976.

[55] Prasasti Kedukan Bukit.

[56] R.J.Wilkinson: A Malay-English Dictionary《马来语-英语词典》, 1932.

[57] Retno Purwanti: Tempo.co; 25 Oktober 2014.

[58] Sarah G.Thomason: 《语言接触导论》, 世界图书出版公司, 2014.

[59] See yuu（西游记）.

[60] Siejenkui（薛仁贵）.

[61] Sultan Muhammad Zainamus: Modern Bahasa Indonesia《印尼语现代词典》.

[62] Teuku Iskandar : Kamus Dewan《马来语德宛词典》, 1970.

[63] Wikipedia; Bangsa Portugis Di Indonesia. 
[64] Yang Kui Yee: Kamus Istilah Baru Bahasa Malaysia《现代马来语（马华双解）词典》, 1984.

\section{Data Penulis}

Nama : Dr. Herman （唐根基）

Program studi : Program Studi S1 Pendidikan Bahasa Mandarin

Perguruan Tinggi: Universitas Universal, Batam-Indonesia（世界大学)

Hp : 081276123377

Email : hermanuvers72@gmail.com 